\title{
KINETIC ENERGY OF A MONOLAYER OF DUST PARTICLES IN GAS DISCHARGE PLASMA
}

\author{
G.E. NORMAN, ${ }^{1,2}$ A.V. TIMOFEEV ${ }^{2,1}$ \\ ${ }^{1}$ Joint Institute for High Temperatures, Russian Academy of Science \\ (13/19, Izhorskaya Str., Moscow 125412, Russia) \\ ${ }^{2}$ Moscow Institute of Physics and Technology (NRU) \\ (9, Institutskii Per., Dolgoprudny, Moscow Region 141700, Russia)
}

\begin{abstract}
The phenomenon of the abnormal heating of oscillations of dust particles in a gas discharge plasma is studied. Equations of motion of of dust particles with allowance for charge fluctuations and the structural features of a near-electrode layer are formulated. The molecular dynamics simulation of the system of dust particles is performed. The mechanism of increase of the average kinetic energy of dust particles in a gas-discharge plasma is proposed. It is shown that charge fluctuations cause forced oscillations, which tend to the warming up of vertical oscillations of dust particles. The combination of parametric and forced resonances can explain the anomalously high values of the kinetic energy of dust particles. The estimated frequency, amplitude, and kinetic energy of oscillations of dust particles are close to the experimental values.
\end{abstract}

\section{Introduction}

The phenomenon of the heating of oscillations of dust particles in a gas discharge plasma to an abnormal kinetic energy is of great interest in the field of dusty plasma [1-3]. Dust particles in a gas discharge plasma acquire a large negative charge and remain stuck in the near-electrode layer. It is found that dust particles in a gas discharge plasma under certain conditions acquire the kinetic energy of the order of $10 \mathrm{eV}$ and above in laboratory experiments [4-13]. This kinetic energy is significantly higher than the ion and electron temperatures in this discharge. Dust particles continue to form a crystalline structure $[7,14,15]$ even with such kinetic energy.

The anomalous heating of oscillations of dust particles in plasma is known since 1996. Several attempts to find the mechanism of this phenomenon is done $[6,8,9,11,12,16-19]$. All of these mechanisms give estimates of the kinetic temperature below the experimental values. Thus, the effect of dust particles oscillation heating to the abnormally high energy remains unresolved. The main difficulties in solving this problem are the system complexity and a number of parameters which cannot be measured exactly at present. The sys- tem complexity lies in the fact that the dust particles system is influenced by many different stochastic and nonlinear phenomena of different nature. Such phenomena make the equations of motion of dust particles intractable analytically. The authors of the papers cited above considered separate phenomena, which produce estimates of the dust particles kinetic energy much lower than the experimental values.

We attempt to explain the abnormal dust particle oscillation heating in this paper. This explanation is based on the phenomena of charge fluctuations of dust particles and the characteristics of the gas discharge nearelectrode layer. In Section 2, the forces and phenomena that determine the dust particles motion are described, and the formulation of the system of equations is performed. In Section 3, the conditions and the results of simulation of the system of dust particles are discussed. The method of molecular dynamics [20,21] allows us to estimate the effects of all known phenomena, including nonlinear and stochastic ones. Varying the parameters of the dust particles motion equations allows us to avoid the problem of lack of exact values of some parameters. Section 4 proposes the scheme of energy transfer from the gas discharge to the dust particles oscillations and further to the gas. In Section 5, the comparison of simulation results and experimental data is performed.

\section{The System of Equations of Motion of Dust Particles}

Let's consider $N$ dust particles forming one horizontal layer in the gas discharge near-electrode layer. Under a dust particle, we mean a sphere of radius $a$ and weight $m$ with charge $Q_{i}=Z_{i} e$, where $i$ is the number of the dust particle, $Z_{i}$ is the charging number, and $e$ is the electron charge. The gravity force is $\mathbf{F}_{\text {grav }}=m \mathbf{g}$, where $g$ is the free fall acceleration. For a case of a low gas pressure, the friction force can be modeled by means of the Langevin thermostat $\mathbf{F}_{\text {fr }}=-2 m \gamma \dot{\mathbf{r}}_{i}+\sqrt{2 m \gamma k_{\mathrm{B}} T_{n} / d t} \xi(t)$, where $\gamma$ 


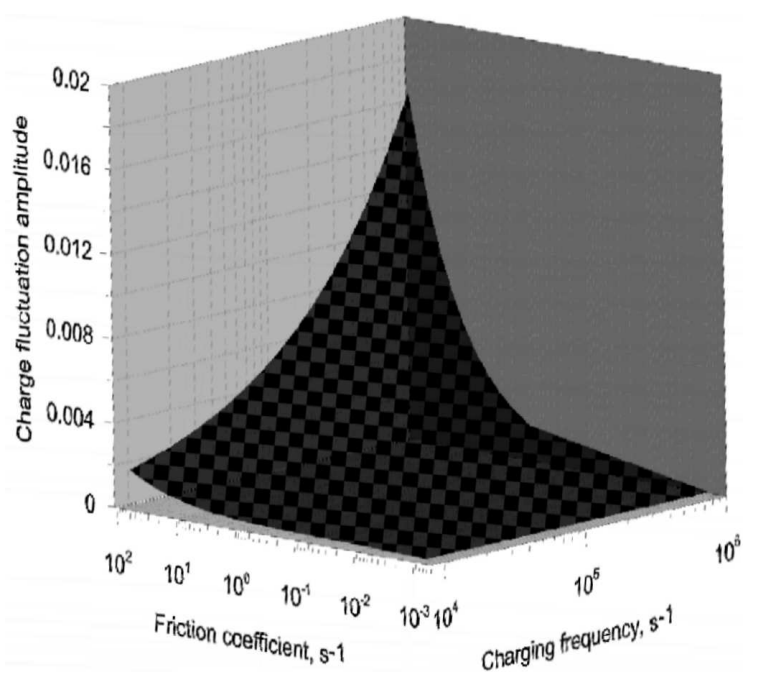

Fig. 1. Image of a surface that separates the zone of abnormal heated dust particles oscillations from the zone of dust particles at room temperature. The schedule is constructed in the coordinates of the friction coefficient $\gamma$, the normalized amplitude of the charge fluctuations $\delta q$, and the characteristic charging frequency $\Omega$

is the friction factor, $k_{\mathrm{B}}$ is the Boltzmann constant, $\mathbf{r}_{i}=$ $\{x, y, z\}$ is the three-dimensional radius-vector of the $i$ th dust particle, $T_{n}$ is the neutral gas temperature, $d t$ is the integration step, $\xi(t)$ is a random function, which has a Gaussian distribution. The Yukawa potential was chosen to be an estimation of the interaction potential of dust particles $U_{i j}\left(\mathbf{r}_{i}-\mathbf{r}_{j}\right) \approx Q_{i} Q_{j} e^{-\kappa\left|\mathbf{r}_{i}-\mathbf{r}_{j}\right|} /\left|\mathbf{r}_{i}-\mathbf{r}_{j}\right|$, where $\kappa$ is a shielding parameter. The potential of a trap is considered parabolic $U_{\text {trap }}=Q_{i} \varepsilon r_{i}^{2}$, where $\varepsilon$ is the potential-trap parameter. The force $\mathbf{F}_{e l}=Q(z, t) \mathbf{E}(z)$ operates from the external vertical electric field $E$ of the near-electrode layer on a charged dust particle. In a gas discharge the near-electrode layer electric field strongly depends on the vertical coordinate as $E(z) \approx\left(1+e^{\prime} z\right)$, where $e^{\prime}$ is the normalized vertical electric field gradient. The charge of a dust particle in plasma is defined by streams of plasma components on the mote surface, therefore it fluctuates in time $Q(\mathbf{r}, t) \approx Q_{e q}(\mathbf{r})+Q_{0} \delta q(t)$, where $Q_{e q}(\mathbf{r})$ is the charge averaged over the time and depending on the coordinate, $Q_{0} \delta q(t)$ is a fluctuating part of the dust particle charge with the correlation function $\left\langle\delta q(t) \delta q\left(t^{\prime}\right)\right\rangle=\delta q^{2} \exp \left(-\Omega\left(t-t^{\prime}\right)\right), \Omega$ is the charging frequency. The normalized amplitude of charge fluctuations $\delta q$ for a standard laboratory experiment is estimated by the formula $\delta q \approx 0.5 / \sqrt{Z}$ [2]. In a gas discharge in plasma, the concentrations of electrons and ions considerably vary over the height in the near-electrode layer and with the distance to a charged dust particle, $Q_{e q}(\mathbf{r}) \approx Q_{0}\left(1+q_{z}^{\prime} z+q_{r}^{\prime}\left(\left|r_{i}-r_{j}\right|-l\right)\right)$, where $q_{z}^{\prime}$ is the normalized dust particle charge gradient in the vertical direction, $q_{r}^{\prime}$ is the normalized charge gradient caused by a change of the concentrations of electrons and ions near the charged dust particle, and $l$ is the average distance between dust particles. Thus, the movement of the system of dust particles is described by the system of equations

$m \ddot{\mathbf{r}}_{i}=\sum \mathbf{F}_{\text {inter }}+\mathbf{F}_{\text {trap }}+\mathbf{F}_{\text {fr }}+\mathbf{F}_{\text {grav }}+\mathbf{F}_{\text {el }}$.

\section{Results of Simulation}

On the basis of the obtained system of equations (1), the molecular dynamics simulation of the motion of dust particles was carried out. The system of equations contains 14 parameters. By varying each of them separately, we obtain the dependence of any characteristic of the system on this parameter. Uniting these dependences, it is possible to deduce the formula for the estimation of the characteristics of the system. We obtained the averaged dependences for the nonideality $\Gamma \approx$ $1.0+(12 \pm 2) 10^{-3} \gamma \Omega N^{0.77} \varepsilon^{0.42} Q^{1.5} e^{-\kappa / 39} /\left(m(g \delta q)^{2}\right)$, kinetic temperature

$K_{v} \approx B m(g \delta q)^{2} /(\gamma \Omega)$,

where $B \approx 1.0+3.5 \times 10^{-6} \Omega+5.7 \times 10^{-5} \delta q^{-2}$, and interparticle distance $\left\langle\Delta r_{i, j}\right\rangle \approx(1.6 \pm 0.4)(1+$ $\left.3 e^{-k / 117}\right)(Q / \varepsilon)^{0.3}$ for the dust particle system for three sets of parameters (see Table).

In formula (2), the kinetic temperature depends only on five parameters: the mass $m$, gravity acceleration $g$, friction coefficient $\gamma$, normalized amplitude of

Ground state $s_{0}$

\begin{tabular}{lccccc}
\hline \multirow{1}{*}{ Parameters } & \multirow{2}{*}{ Symbol } & \multicolumn{3}{c}{ Magnitude } \\
\cline { 3 - 5 } & & Set N1 & Set N2 & Set N3 \\
\hline number of particles & $N$ & 3 and 11 & 7 and 13 & 18 \\
integration step & $d t, \mathrm{~s}$ & $10^{-6}$ & $10^{-6}$ & $10^{-6}$ \\
dust particle radius & $a, 10^{-4} \mathrm{~cm}$ & 4.0 & 10.0 & 8.0 \\
dust particle density & $\rho, \mathrm{g} / \mathrm{cm}^{3}$ & 1.5 & 1.5 & 1.5 \\
gravity & $g, \mathrm{~cm}^{2}$ & 980 & 980 & 980 \\
friction coefficient & $\gamma, \mathrm{s}^{-1}$ & 1.0 & 3.0 & 2.0 \\
dust particle charge & $Q, \mathrm{el}^{-1} \mathrm{ch}^{-}$ & $2 \times 10^{3}$ & $1 \times 10^{4}$ & $1 \times 10^{4}$ \\
charge vertical gradient & $q_{z}^{\prime}, \mathrm{cm}^{-1}$ & 0.10 & 0.05 & 0.10 \\
charge radial gradient & $q_{r}^{\prime}, \mathrm{cm}^{-1}$ & -0.1 & -0.3 & -0.1 \\
charge fluctuation & $\delta q$ & 0.011 & 0.005 & 0.065 \\
electric field gradient & $e_{z}^{\prime}, \mathrm{cm}^{-1}$ & -40.0 & -30.0 & -40.0 \\
charging frequency & $\Omega, \mathrm{s}^{-1}$ & $2 \times 10^{4}$ & $1 \times 10^{5}$ & $2 \times 10^{5}$ \\
screening parameter & $\kappa, \mathrm{cm}^{-1}$ & 10.0 & 5.0 & 20.0 \\
trap parameter & $\varepsilon, \mathrm{ab} . \mathrm{unnits}^{-1}$ & $3 \times 10^{-2}$ & $9 \times 10^{-2}$ & $5 \times 10^{-2}$ \\
\hline
\end{tabular}




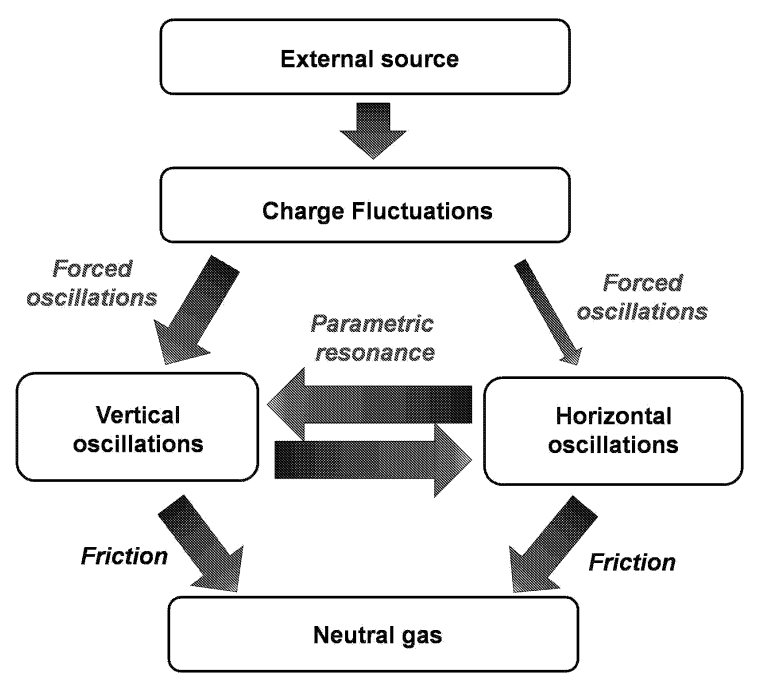

Fig. 2. Scheme of energy transfer from the gas discharge to the dust particles

charge fluctuations $\delta q$, and the characteristic charging frequency $(\Omega)$. Considering the dust particle mass and the value of gravity acceleration to be strictly defined, we can construct a surface in the grid of parameters $\gamma$, $\delta q$, and $(\Omega)$, where the dust particles kinetic temperature separated from the ambient gas temperature. Assuming that the gas temperature is room one, and the dust particles correspond to the second set of parameters (Table), we obtain the schedule of the surface that separates the zone of anomalous heating of dust particles from the zone of dust particles at room temperature (Fig. 1). The kinetic temperature of dust particles in the simulation never falls below the neutral gas temperature, because the model takes into account the interaction of the neutral gas with the Langevin thermostat.

In addition, some interest dependence of the spectrum and the average kinetic energy of oscillations of dust particles on the parameters of the interaction potential should be noted. In the simulation, we used the Yukawa potential and the sum of two screened Coulomb potentials [22]. For the screening of various parameters, we calculated the spectra of fluctuations and the average kinetic energy. It was found that the vibrational spectrum of dust particles and the average kinetic energy of vertical oscillations are virtually independent of the screening parameter. Thus, the simulation shows the independence of the vibrational spectrum of dust particles from the interaction potential of dust particles in the framework of the model chosen for the case of "heated" dust particles.

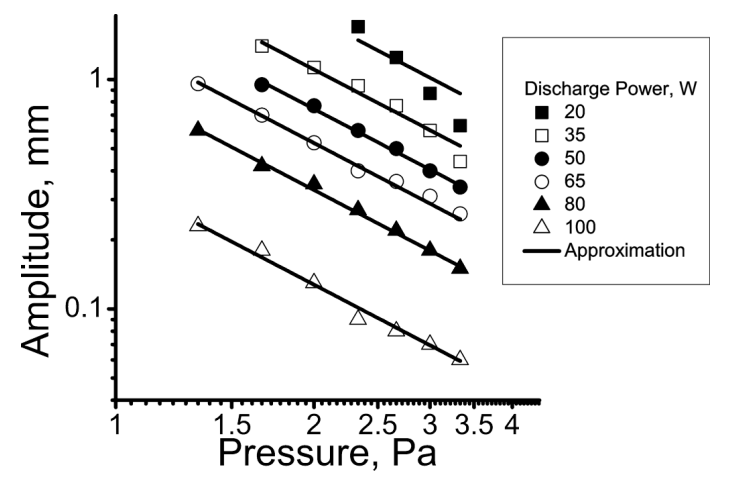

Fig. 3. The amplitude of dust particle vertical oscillations at different gas pressures and discharge powers. Experimental data is signed by points. Approximation is depicted by solid curves

\section{The Scheme of Energy Transfer in Plasma-Dust System}

The general scheme of heating is shown in Fig. 2. The external source supports the gas discharge, which provides, in turn, the charge fluctuations of dust particles. Charge fluctuations lead to the occurrence of the exciting force. The pumping of energy by the exciting force into the vertical motion and slightly into the horizontal motion of dust particles becomes possible due to the overlapping of the frequency ranges of charge fluctuations force and vertical natural oscillations of the system of dust particles [23]. The large amplitude of dust particle oscillations leads to the occurrence of nonlinear terms. The crystalline order of the plasma-dust system, nonlinear effects, the form of the system of equations (1), and the overlapping of the frequency ranges of vertical and horizontal oscillations indicate the parametric resonance. It supports the exchange of energy between the horizontal and vertical oscillations. Note that the pumping of horizontal oscillations occurs at a frequency of vertical oscillations, and the frequency of vertical oscillations is mainly determined by the sheath parameters. The balance between the energy loss due to the friction and the energy inflow determines the amplitude and the kinetic energy of dust particles.

\section{Comparison with Experiments}

The frequency $\omega_{z}=\sqrt{-g\left(e_{z}^{\prime}+q_{z}^{\prime}\right)}$ of dust particle oscillations in the near-electrode layer is close to experimental values and explains the small width of the range of vertical oscillatory frequencies of dust particles obtained from experimental data. Experimental data on the frequencies of dust particle oscillations fall into estimated frequency range $\omega_{z} \approx 20 \div 170 \mathrm{~s}^{-1}$. 
The vertical oscillation amplitude $A_{z} \approx$ $\sqrt{5 m(g \delta q)^{2} /(2 \gamma \Omega)}$ has a power dependence on the neutral gas pressure $A_{z} \propto p^{-1,5}$ for the typical conditions of laboratory experiments on dusty plasma. The approximation of experimental data [8] (Fig. 3) confirms the gained dependence and gives the dependence of the oscillation amplitude on the discharge power $A_{z}(p, W)_{[\mathrm{mm}]} \approx\left(-0.9+145 W_{[\mathrm{W}]}^{-1.0}\right) p_{[\mathrm{Pa}]}^{-1.5}$, where $W$ is discharge power. The numerical evaluation of the temperature is also close to experimental values:

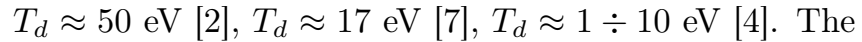
prevalence of the vertical amplitude over the horizontal one has also proved to be true for the experimental data [9].

\section{Conclusions}

Equations of motion of dust particles in a gas discharge with allowance for charge fluctuations and the structural features of the near-electrode layer are formulated. The theoretical analysis and the MD simulation of the system of dust particles are performed. The following results are obtained.

1. The formulas relating the coupling parameter, kinetic temperature, and interparticle distance to the parameters of the system.

2. The scheme of energy transfer from the gas discharge to vertical oscillations and then to horizontal ones and then to the neutral gas.

3. Five parameters determining the dust particle kinetic temperature for the case of "hot" dust particles oscillations. The three parameters (mass, gravity acceleration, and friction coefficient) are known accurately enough. Two more parameters (dust particle charge fluctuation amplitude and charging frequency) are impossible to find out from an experiment with sufficient accuracy. These parameters can only be estimated. The assessment of these parameters using the value of kinetic temperature and the derived formula give a new method for obtaining these parameters.

4. The independence of several dynamical properties of a plasma-dust crystal is shown for the case of oscillations of "hot" dust particles.

The estimates of frequency, amplitude, and kinetic temperature of oscillations of dust particles are in the satisfactory agreement with the experimental values.
The authors acknowledge the fruitful discussions with S.I. Popel concerning charge fluctuation, with I.V. Schweigert on forced oscillations, and with V.V. Stegailov. This work is partially supported by the RAS programs 2 (coord. V.E. Fortov), 13 (coord. G.I. Savin), OEM12 (coord. D.M. Klimov) and the Federal Special Program under contract 02.740.11.0236 (coord. V.E. Fortov).

1. V.E. Fortov, A.G. Khrapak, S.A. Khrapak, V.I. Molotkov, and O.F. Petrov, Phys. Usp. 47, 447 (2004).

2. V. Tsytovich, G. Morfill, S. Vladimirov, and H. Thomas, Elementary Physics of Complex Plasmas (Springer, New York, 2008).

3. O.S. Vaulina, O.F. Petrov, V.E. Fortov, S.A. Khrapak, and A.G. Khrapak, Dusty Plasmas: Experiment and Theory (Fizmatlit, Moscow, 2009) (in Russian).

4. V.A. Schweigert, I.V. Schweigert, A. Melzer, A. Homann, and A. Piel, Phys. Rev. E 54, 4155 (1996).

5. Y. Ivanov and A. Melzer, Phys. of Plasmas 12, 072110 (2005).

6. A. Melzer, A. Homann, and A. Piel, Phys. Rev. E 53, 2757 (1996).

7. V.A. Schweigert, I.V. Schweigert, V. Nosenko, and J. Goree, Phys. of Plasmas 9, 4465 (2002).

8. R.A. Quinn and J. Goree, Phys. of Plasmas 7, 3904 (2000).

9. A. Samarian, B. James, S. Vladimirov, and N. Cramer, Phys. Rev. E 64, 025402 (2001).

10. V. Zhakhovskii, V. Molotkov, A. Nefedov, V. Torchinskiy, A. Khrapak, and V. Fortov, JETP Lett. 66, 419 (1997).

11. R.A. Quinn and J. Goree, Phys. Rev. E. 61, 3033 (2000).

12. S. Nunomura, T. Misawa, N. Ohno, and S. Takamura, Phys. Rev. Lett. 831970 (1999).

13. H. Totsuji, C. Totsuji, and K. Tsuruta, Phys. Rev. E. 64, 066402 (2001).

14. D. Samsonov, S.K. Zhdanov, R.A. Quinn, S.I. Popel, and G.E. Morfill, Phys. Rev. Lett. 92, 255004 (2004).

15. V.A. Schweigert, V.M. Bedanov, I.V. Schweigert, A. Melzer, A. Homann, and A. Piel, JETP 88, 482 (1999).

16. O.S Vaulina, A.Yu. Repin, O.F. Petrov, and K.G. Adamovich, JETP 102, 986 (2006). 
17. U. de Angelis, A. Ivlev, G. Morfill, and V. Tsytovich, Phys. of Plasmas 12, 052301 (2005).

18. A. Ivlev, S. Zhdanov, B. Klumov, and G. Morfill, Phys. of Plasmas 12, 092104 (2005).

19. G. Norman, V. Stegailov, and A. Timofeev, Contrib. to Plasma Physics 50, 104 (2010).

20. A.M. Ignatov, S.A. Maiorov, S.A. Trigger, and P.P.J.M. Schram, in Proceed. of 33-rd EPS Conference on Plasma Phys., 301, (2006), p. 1.

21. B.A. Klumov, M. Rubin-Zuzic, and G.E. Morfill, JETP Letters 84, 542 (2007).

22. A.V. Filippov, A.G. Zagorodny, A.F. Pal', and A.N. Starostin, JETP Letters 81, 146 (2005).

23. L.D. Landau and E.M. Lifshitz, Mechanics (Pergamon Press, Oxford, 1987).

Received 22.10.10

\section{КІНЕТИЧНА ЕНЕРГІЯ МОНОШАРУ ПИЛОВИХ} ЧАСТИНОК У ПЛАЗМІ ГАЗОВОГО РОЗРЯДУ

Г.Е. Норман, О.В. Тимофеєв

$\mathrm{P}$ е $з$ ю м е

Розглянуто явище аномального розігріву руху пилових частинок у газорозрядній плазмі. Сформульовано рівняння руху пилових частинок з урахуванням флуктуацій заряду і особливостей приелектродного шару розряду. Систему пилових частинок модулюють за допомогою методу молекулярної динаміки. Запропоновано механізм збільшення середньої кінетичної енергії коливань пилових частинок у газорозрядній плазмі. Показано, що флуктуації заряду є причиною вимушених коливань, які приводять до розігріву вертикальних коливань частинок пилу. Комбінація параметричного резонансу і вимушених коливань може пояснити аномально високі значення кінетичної енергії пилових частинок. Оцінювання частоти, амплітуди і кінетичної енергії коливань пилових частинок близьке до експериментальних значень. 